\title{
Interfaces gráficas para dispositivos móveis na educação a distância (EAD)
}

Fabiana Lemos da Silva é graduada em Letras pela Universidade Nove de Julho, especialista em Língua Portuguesa e Literatura pela Universidade Paulista, Mestre em Design pela Universidade Anhembi Morumbi. Atuante na área de Ensino a Distância (EAD) desde 2012, com foco em desenvolvimento de produtos e conteúdos digitais educativos. <fabianalemos@gmail.com> ORCID: 0000-0002-4114-8533
Resumo A EAD é uma modalidade de ensino que atualmente carece de subsídios tecnológicos para que possa promover as trocas e interações necessárias. Nesse sentido, tem-se as interfaces gráficas que atuam como uma porta entre os usuários e o mundo digital. Tais interfaces vêm ganhando bastante destaque nas tecnologias móveis na contemporaneidade devido ao uso dos smartphones também no contexto educativo. Dessa forma, nesse estudo, por meio de uma pesquisa investigativa, é analisado o cenário da EAD e a atuação dos designers na confecção e aprimoramento das Interfaces Gráficas, bem como as possibilidades que esse novo contexto da tecnologia móvel apresenta para as práticas projetuais do design.

Palavras chave Educação a Distância, Interfaces Gráficas Móveis, Smartphones, Experiência do Usuário. 


\section{Ensino do Design}

Milton Sogabe é Graduado em Artes

Plásticas, na FAAP-SP, mestrado e dou-

torado em Comunicação e Semiótica, na

PUC-SP e pós-doutorado na Universidade de Aveiro, em Portugal. Docente aposentado do Instituto de Artes, da UNESP e desde 2017, docente do PPG Design da Universidade Anhembi Morumbi. Bolsista Produtividade 2 do CNPq. <miltonsogabe@gmail.com>

ORCID: 0000-0003-1286-9013

\section{Graphic Interfaces for Mobile Devices in E-Learning}

Abstract E-learning is a modality that currently lacks technological subsidies so that it can promote the necessary exchanges and interactions. In this sense, there are the graphical interfaces that act as a door between users and the digital world, such interfaces have been gaining prominence in contemporary mobile technologies due to the use of smartphones also in the educational context. Thus, in this study, through an investigative research, E-learning scenario is analyzed and the performance of designers in the making and improvement of the Graphic Interfaces, as well as the possibilities that this new context of mobile technology presents for the design practices of design .

Keywords E-learning, Mobile Graphical Interfaces, Smartphones, User Experience.

\section{Interfaces Gráficas para Dispositivos Móviles en Educación a Distancia (EAD)}

Resumen EAD es una modalidad de enseñanza que actualmente carece de subsidios tecnológicos para que pueda promover los intercambios e interacciones necesarios. En este sentido, existen interfaces gráficas que actúan como una puerta de enlace entre los usuarios y el mundo digital, tales interfaces han ganado importancia en las tecnologías móviles hoy en día por lo uso de teléfonos inteligentes también en el contexto educativo. Por lo tanto, en este estudio, a través de una investigación, analizaremos el escenario de EAD y el papel de los diseñadores en la creación y mejora de las interfaces gráficas, así como las posibilidades que este nuevo contexto de tecnología móvil presenta para las prácticas del diseño.

Palabras clave Educación a distancia, Interfaces gráficas móviles, Teléfonos inteligentes, Experiencia del usuario. 


\section{Introdução}

No contexto da pandemia do Coronavírus, a continuidade das aulas através do ensino a distância se fez necessária, repentinamente. Assim os docentes e estudantes também tiveram de aprender e se adaptar, da noite para o dia, nesse ambiente de ensino-aprendizagem. Surgiu a percepção de um tempo e espaço diferenciado, da situação de conectividade e dispositivos dos estudantes e a descoberta das possibilidades desse meio, forçando-nos a conhecer e utilizar aspectos da Educação a Distância (EAD), que provavelmente serão mais utilizados no mundo pós-pandemia, do século XXI. Este fato afeta não só o campo da educação, mas todas as atividades do nosso cotidiano.

No campo da educação, já era uma discussão que acontecia no sentido das incertezas relacionadas ao futuro da educação e quanto ao tipo de formação que crianças, jovens e adultos precisam ter nesse contexto digital em que vivemos.

Essa preocupação deve-se ao fato de a instituição escolar ter como responsabilidade não somente a formação intelectual do indivíduo, mas também uma formação mais sólida que o capacite para atuar como cidadão em uma sociedade.

Nesse sentido, é importante que haja uma mudança considerável no modo de pensar a educação escolar, visto que na era digital, pois os conteúdos e referências emergem da vida, que se insere dentro da escola, sem barreiras que separam o cotidiano da educação escolar, conforme relatam os especialistas sobre a escola contemporânea:

\footnotetext{
O mundo mudou e a escola vive os problemas e dilemas da transição das eras. A discussão universal sobre a qualidade da educação escolar contemporânea, em que todos se queixam - pais, alunos, sociedade, a própria escola - revela o desconforto provocado pela crise paradigmática (ABREU; EISENSTEIN; ESTEFENON, 2013, p. 141).
}

Com o advento das tecnologias digitais, atuando fortemente no ramo educacional, tem-se a possibilidade de instalar uma abordagem unificadora com a ajuda de metodologias e procedimentos disponíveis nos diversos campos do conhecimento. A internet, nesse sentido, é a ferramenta coletiva que será capaz de conduzir essa empreitada, tendo sempre como ponto de apoio o indivíduo em sua coletividade.

Nesse novo contexto da educação, os estudantes muitas vezes aprendem seguindo seus próprios métodos, por meio de caminhos que eles mesmos decidem, têm possibilidade de imersão e participação na construção de conhecimentos, onde poderá escolher os caminhos que irá seguir para descobrir o conteúdo que deseja consultar, mesmo que esse esteja distribuído de maneira não-linear em sites, livros, revistas, vídeos, entre outros meios. $O$ contexto do professor que transfere o conteúdo para o aluno, 
fica ainda mais questionado nesta situação, visto que o aluno caminha cada vez mais para uma autonomia e o professor transforma-se em um mediador nesse percurso da construção do conhecimento.

O espaço da sala de aula deixa de ser o único espaço onde o conhecimento é adquirido, mesclando-se cada vez mais ao ciberespaço e borrando as fronteiras entre este e o espaço físico. Na sociedade da informação, se faz cada vez mais presente e disponível através dos dispositivos móveis conectados numa rede mundial, onde todos somos "prossumidores", ou seja, consumidores e produtores de informações simultaneamente (TOFFLER, 1995).

Por meio das Tecnologias da Informação e da Comunicação (TICs), os processos de aprendizagem invadem todas as áreas da vida social, pessoal e econômica. A nova dimensão da educação, que melhor se expressa pelo termo "aprendizagem" atinge todas as organizações, seja de caráter acadêmico ou comercial.

Assim, a Educação a Distância (EAD) ganha cada vez mais visibilidade, tendo em vista que suscita a ideia de autonomia e protagonismo por parte dos próprios estudantes. Interações que antes se davam principalmente nos meios físicos e sociais, mas que passaram a ocorrer também por intermédio da tecnologia e dos diferentes dispositivos, com destaque às tecnologias móveis e seus aplicativos que vem se destacando cada vez mais na atualidade, conforme veremos.

\section{A EAD frente às tecnologias digitais - TICs e Ciberespaço}

O ciberespaço que parecia apenas um conceito abstrato, com a pandemia do Corona Vírus, desvelou-se e concretizou-se no cotidiano da maioria de pessoas, principalmente os estudantes e professores que continuaram suas vidas acadêmicas, de forma remota, através das TICs.

As tecnologias sempre afetaram a Educação, na relação com as mudanças no modo de produção, armazenamento e divulgação de informação, assim como nas mídias de acesso a esses conteúdos. Porém, a tecnologia digital acontece numa aceleração tal que se torna difícil a sua adaptação pela Educação, em um curto espaço de tempo, com o surgimento de uma geração de nativos digitais (PRENSKY, 2001), que cresceu respirando esse ambiente, em contraste com professores que se formaram, mesmo antes da Internet.

Para Lévy (1999, p. 167) o ciberespaço, suas comunidades virtuais, suas reservas de imagens, suas simulações interativas, sua irresistível proliferação de textos e de signos, é o mediador essencial da inteligência coletiva da humanidade.

Nesse contexto, ainda segundo o autor, "os sistemas educativos encontram-se hoje submetidos a uma gama de quantidade e diversidade de ferramentas, impulsionando cada vez mais a evolução dos saberes" (LÉVY, 1999, p. 167). 
Para Tori (2010 apud AMARAL; GONÇALVES, 2020, p. 206), demarca-se que a cooperação entre métodos e técnicas presenciais e virtuais no ensino podem auxiliar no acompanha- mento do desenvolvimento da aprendizagem, incentivar práticas colaborativas, motivar e envolver os alunos.

A Educação a Distância (EAD) é produto desse contexto e ganha cada vez mais espaço na sociedade contemporânea, conforme mostram os dados do último Censo da Associação Brasileira de Educação a Distância (ABED), onde o número de alunos $\mathrm{EAD}$, considerando todos os cursos, passou de 9 milhões.

Além disso, a modalidade também é vista também como uma alternativa ao atendimento do grande público, a quem o acesso ao sistema presencial e tradicional e permanência nele são dificultados por diversos motivos, tais como localidade, recursos financeiros, deslocamento, acessibilidade, entre outros.

Para Lévy (1999, p. 24), a EAD explora as hipermídias, as redes de comunicação interativas e todas as tecnologias intelectuais da cibercultura, mas para o autor o essencial se encontra na possibilidade de um novo estilo de pedagogia, que favorece ao mesmo tempo as aprendizagens personalizadas e a aprendizagem coletiva em rede. Nesse contexto, o professor deixa de ser apenas um fornecedor direto de conhecimentos e passa a ser coprodutor, junto aos alunos.

Quando a aprendizagem é concebida como um processo de construção do conhecimento, ela o trata como algo aberto, conforme pontuam os autores:

\footnotetext{
As estratégias de ensino devem ser planejadas a fim de propiciar situações que viabilizem posicionamentos críticos, proponham problemas e questões como pontos de partida para discussões. Essas estratégias devem também provocar a necessidade de busca de informação, enfatizando a manipulação do conhecimento, otimizando a argumentação para a provocação de pontos de vista, dissolvendo receitas prontas e desmistificando o erro (FORMIGA; LITTO, 2009, p. 216).
}

Atualmente, acredita-se na capacidade da construção do conhecimento de forma colaborativa, bem como no comprometimento dos estudantes por meio de novas interfaces e plataformas de ensino.

Para a condução dessa modalidade, é necessário o uso de ferramentas que atuem em compasso com a interatividade do meio digital, que permita a interação com todos os componentes educativos e os mais diversos tipos de informações. Ao longo dos anos tem-se adotado diferentes ferramentas para esse propósito, sendo que a EAD se manteve durante muitos anos tendo como aporte tecnológico os computadores pessoais, por algum tempo os tablets ganharam alguma notoriedade no ramo, mas não obteve assim tanto sucesso. No entanto, atualmente 
$\mathrm{Na}$ era da comunicação e da informação praticamente tudo o que buscamos ou precisamos localizar se encontram a somente alguns cliques. $\mathrm{O}$ acesso às informações reconfigurou-se tendo em vista que, por meio do computador e da internet, tudo é acessado de maneira muito mais fácil se comparado a outros períodos.

$\mathrm{Na} E A D$, além do computador e da internet, é necessário ainda que haja um meio pelo qual seja possível acessar as informações e dados de modo organizado, além de um ambiente que promova a interação com os colegas e professores. Todas essas aplicações ocorrem por meio de um Ambiente Virtual de Aprendizagem (AVA), que tem a missão de disponibilizar ao estudante ou usuário todos os elementos que necessita, para que seu aprendizado se dê de modo eficaz. Entretanto, para que a comunicação entre o mundo digital (AVA) e mundo físico (estudante) seja efetiva, deve-se dispor de um elemento que possibilite essa interação, esse elemento é a Interface Gráfica do Usuário.

A interface é, portanto, o meio pelo qual o usuário se comunica com o sistema para realizar suas tarefas (JOHNSON, 2001, p. 17). Ela tem como objetivo proporcionar a interação mais amigável possível entre as pessoas e os computadores, por meio de ícones e elementos dispostos na tela dos computadores e dispositivos tecnológicos.

\section{Design aplicado às Interfaces Gráficas na EAD}

No contexto da Educação a Distância atua-se por meio de dados e informações que são transmitidas das mais diversas maneiras aos usuários/ estudantes por meio de suportes digitais e eletrônicos. Tais mecanismos transmitem informações que, articuladas a estratégias pedagógicas, podem vir a se converter em conhecimentos adquiridos.

Tem-se, nesse contexto, a interlocução de diferentes áreas que atuam em sincronia, a fim de transmitir tais informações de modo didático, ou seja, organizados e estruturados com base em referenciais pedagógicos. Um desses campos de atuação refere-se ao Design, em suas mais diversas ramificações e manifestações dentro do contexto da EAD.

Dados, informações e conhecimentos são tratados como entidades abstratas, separadas de sua base material e do processo de transmissão que incluem, inevitavelmente, componentes do design. "Da mesma maneira que não existe aprendizagem sem conteúdo, não existe uma mediação de informação com textos e imagens sem substrato material de suporte" (BONSIEPE, 2011, p. 34). Nesse contexto, a interferência do design pode se dar no sentido de facilitar a recepção e interpretação de tais dados ou informações por meio das interfaces.

Chamados por Bonsiepe (2011, p. 37) de aspectos formais, apesar de nem sempre receber a importância que deveriam, muitas vezes são esses aspectos os responsáveis pela transmissão eficaz dos conteúdos, "permitindo uma ação mais eficiente, pois a apresentação de conhecimentos requer 
a intervenção de atos projetuais, e essa mediação ocorre por meio de uma Interface Gráfica". Nesse sentido, a interface no ciberespaço se torna extremamente importante, porque nele tudo é interface, ou seja, tudo é design.

o design, muitas vezes é orientado à interação entre usuário e o produto, dessa forma, pode-se dizer que o domínio do design é o domínio da interface.

\begin{abstract}
A interface não é uma coisa, mas sim um espaço no qual se estrutura a interação entre corpo, ferramenta e objetivo da ação. A interface revela o caráter de ferramenta dos objetos e o conteúdo comunicativo das informações. A interface transforma objetos em produto e esse é exatamente esse o domínio central do design. A interface transforma sinais em informação interpretável. A interface transforma simples presença física em disponibilidade (BONSIEPE, 2015, p. 110).
\end{abstract}

Cada vez mais as interfaces gráficas educativas valem-se da interação dos mais diversos elementos - texto, imagens, sons, movimentos - de modo a possibilitar ao usuário/estudante diferentes maneiras de ter contato com a informação. No entanto, a primeira leitura, a primeira impressão e o primeiro impacto ainda acontecem por meio de formas, cores e composições visuais.

Construir uma interface gráfica é, antes de qualquer coisa, criar formas. Serão estas formas que conduzirão o usuário para um determinado conteúdo e que serão capazes de agregar uma experiência sensorial a este processo de apreensão (CAMPOS; PRIOSTE, 2005, p. 4).

Nas Interfaces Gráficas, o modo não linear como as informações são apresentadas de maneira visual fazem da informação virtual um caminho múltiplo a ser definido pelo próprio usuário.

Nesse sentido, resgata-se o conceito de visualidade, onde Dondi (1997, p. 52) destaca que "dentre todos os meios de comunicação humana, o visual é o único que não dispõe de um conjunto de normas e preceitos, de metodologia e de nenhum único sistema com critérios definidos, tanto para expressão quando para o entendimento dos métodos visuais".

Uma das melhores maneiras de facilitar o rápido entendimento de uma página web, por exemplo, é assegurar que a aparência das coisas e todas as dicas visuais sejam claras e demonstrem exatamente as relações entre os conteúdos das páginas, o que está relacionado e quais são suas partes. Em outras palavras, para ele, cada página deve ter uma hierarquia visual clara (KRUG, 2001, p. 31). 
De acordo com Bonsiepe (2015, p. 22), a interface é o domínio do acoplamento estrutural entre ferramenta e usuário. Nesse sentido, o autor relata que a interface é para o programa o que o cabo é para o martelo. Esse acoplamento ocorre em primeiro lugar através do espaço retinal. A noção look and feel se refere a esse processo de acoplamento entre corpo e ferramenta através da percepção visual.

Para o autor, o espaço retinal é estruturado por meio de qualidades gráficas, tais como: forma, cor, tamanho, posição, orientação, textura, transições ou transformações no tempo.

Com o objetivo de proporcionar a interação mais amigável possível entre as pessoas e os dispositivos tecnológicos, as interfaces gráficas ou gráfico-digitais se tornam cada vez mais presentes no cotidiano, devido ao desenvolvimento tecnológico e o consequente aumento da disseminação de informações em diferentes suportes. Um desses dispositivos que cada vez mais ganham espaço entre as pessoas são os celulares smartphones que com o passar dos anos ganham cada vez mais funções e assim assumem um lugar de destaque na sociedade contemporânea.

\section{Interfaces Gráficas na EAD - Tecnologia Móvel e suas Aplicações}

Atualmente, a maioria das pessoas possui um celular smartphone, dispositivo móvel, que tem se tornando a ferramenta tecnológica mais usa$\mathrm{da}$, entre crianças, adultos e idosos. Os smartphones possibilitam atuar em compasso com a interatividade do meio digital, permitem a interação com todos os elementos e componentes desse contexto, além de tornar viável o acesso aos mais diversos tipos de informações.

Ao longo dos anos, evidenciou-se um decréscimo no uso de computadores e um crescimento no uso de celulares para acesso à Internet, que atinge $3 \mathrm{em}$ cada 4 casas no Brasil. A figura 1 apresenta que o maior uso da Internet é para o envio e recebimento de mensagens de texto, voz ou imagem através de aplicativos (IBGE, 2020).

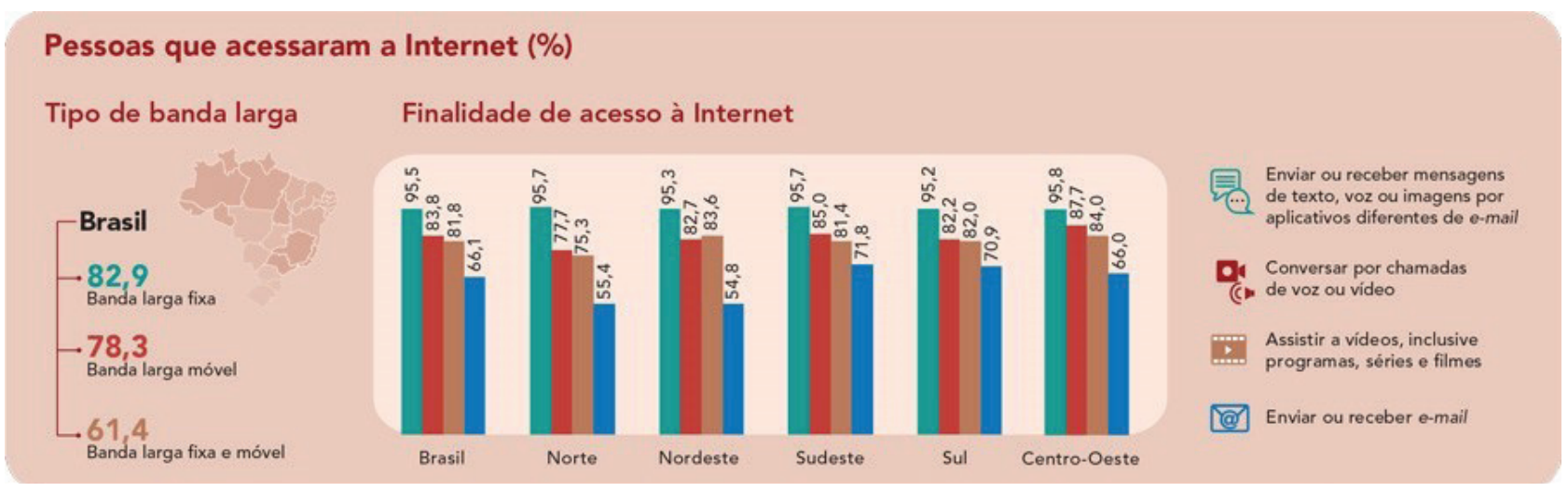

Fig 1. Pessoas que acessaram a Internet (\%)

Fonte: IBGE, 2017 
No Brasil, em 2017, o acesso à Internet acontece na sua grande maioria através de celulares, conforme mostram os dados abaixo trazidos pelo Instituto Brasileiro de Geografia e Estatística (IBGE).

Em 98,7\% dos domicílios em que havia acesso à Internet, o telefone móvel celular era utilizado para este fim. Em seguida, estava o microcomputador (52,3\%). A televisão foi usada em 16,1\% dos domicílios em que havia acesso à Internet, e o tablet em 15,5\% (IBGE, 2020).

De acordo com $30^{\mathrm{a}}$ Pesquisa Anual do FGVcia da FGV/EAESP de 2019, atualmente tem-se 230 milhões de celulares inteligentes (smartphones) em uso no Brasil. Adicionando os Notebooks e os Tablets são 324 milhões de Dispositivos Portáteis em maio de 2019, ou seja, 1,6 dispositivo portátil por habitante (FGV-EAESP, 2019).

Os resultados divulgados comprovam o processo de informatização e digitalização das empresas e da sociedade, com base em uma amostra de 2.602 médias e grandes empresas.

Diante de tais dados, evidencia-se, portanto, um cenário em que os sistemas móveis e seus aplicativos, principalmente por meio dos smartphones assumem uma posição de protagonistas nas inúmeras ações executadas no dia a dia. Por meio dos smartphones é possível fazer compras das mais diversas naturezas, realizar movimentações bancárias, receber e enviar informações de todos os lugares e das mais diversas formas, conectar-se com as pessoas de qualquer lugar e diversas outras atividades.

Ao longo dos anos vê-se um uso constante dos aparelhos celulares e suas aplicações também no meio educacional, apoiando diferentes processos de ensino-aprendizagem.

Sobral (2011 apud AMARAL; GONÇALVES, 2020, p. 206) defende que o uso de qualquer ferramenta tecnológica, desde que objetive o desenvolvimento ético, criativo e expressivo dos alunos e que esteja inserida em um projeto pedagógico consistente, deve ser utilizada como uma nova estratégia para o ensino e aprendizagem.

O Edmodo, por exemplo, é um desses casos, visto que se trata de uma plataforma de aprendizagem social para professores, alunos e pais (EDMODO, online), seu o acesso é disponibilizado por meio do aplicativo ou por meio do site. É considerado atualmente a principal rede social desse âmbito e oferece uma interface repleta de funcionalidades específicas para cada um desses perfis, personalizando as informações e ações por meio de uma interface simples e intuitiva.

Outra interface bastante conhecida, tendo seu principal público por meio do aplicativo, é o Duolingo, um aplicativo de ensino de línguas que proporciona ao usuário uma experiência "gamificada" para aquisição de vocabulário, expressões e frases em inúmeras línguas. 
A apresentação presente no site do Duolingo é a seguinte: "Aprender com o Duolingo é divertido e viciante. Ganhe pontos ao acertar, corra contra o tempo e passe de nível. As nossas aulas são curtinhas e eficazes, e nós temos provas de elas que funcionam mesmo" (DUOLINGO, 2020, online).

Um outro exemplo mais recente é referente ao aplicativo da rede pública de ensino disponibilizado aos estudantes brasileiros a partir de abril de 2020, devido à pandemia do Corona Vírus. Para subsidiar as aulas presenciais o governo disponibilizou um aplicativo para os estudantes, no qual é possível assistir às aulas ao vivo e baixar os materiais didáticos.

A interface do aplicativo da rede pública de São Paulo é simples, onde o conteúdo é basicamente separado por grupos, como se fossem salas de aula, conforme mostra a Figura 2 abaixo:

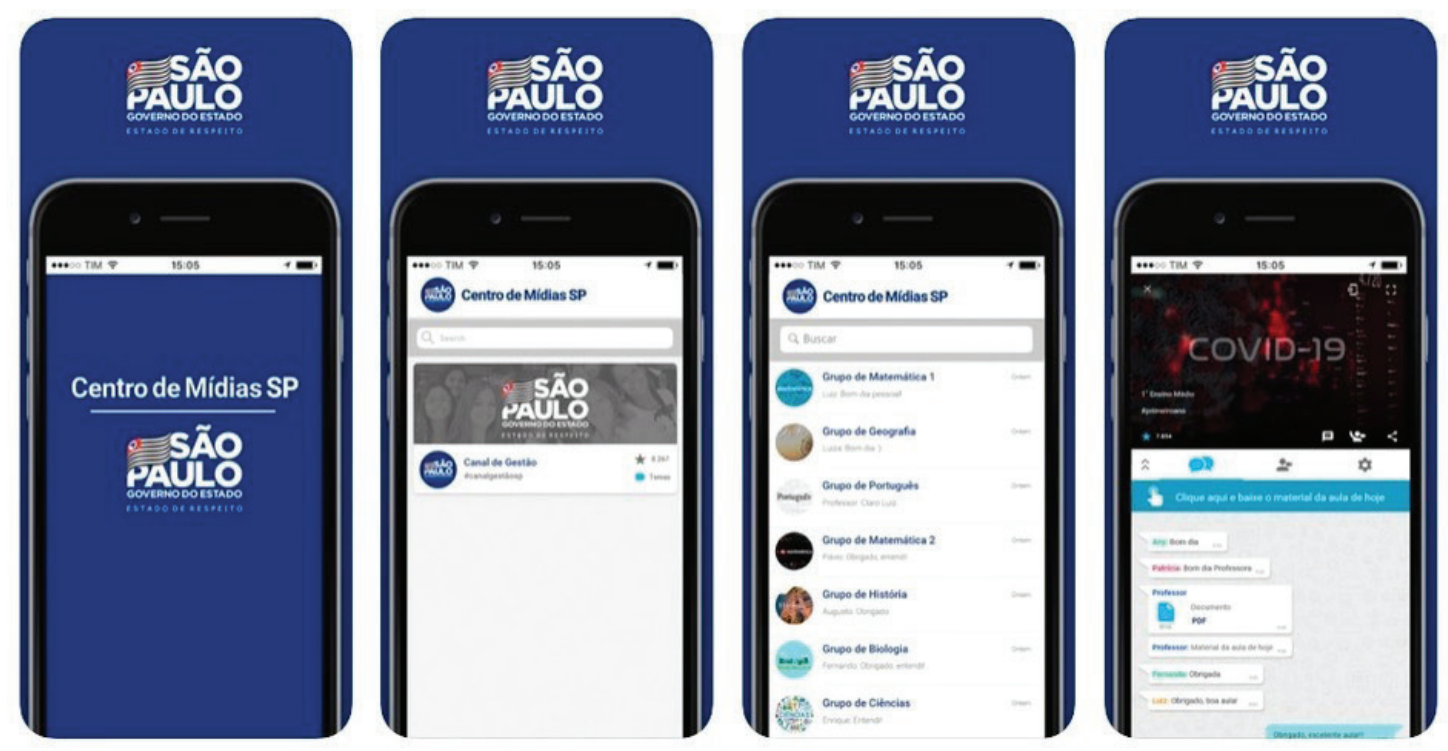

Fig 2. Interface do Aplicativo da Rede Pública de Ensino do Estado de São Paulo | Fonte: GLOBO-G1, 2020

De acordo com Rossieli, Secretário de Estado da Educação, pensado na lógica de uma rede social, este aplicativo permite grande interação entre professores e estudantes. Ele irá auxiliar para que os professores estejam o mais próximo possível de cada um dos nossos 3,5 milhões de estudantes e isso vai acontecer graças à tecnologia, que deve ser cada vez mais uma grande aliada da educação (G1-GLOBO, 2020, online).

Diante de todos os casos apresentados, vê-se, portanto, um ramo bastante promissor de atuação dos designers, tendo em vista que esses profissionais, em parceria com os desenvolvedores, estão presentes na confec- 
ção e aprimoramento das interfaces gráficas utilizadas em todos os âmbitos. Em suas diversas ramificações, os designers atuam nas funcionalidades, recursos e elementos composicionais, das interfaces gráficas, além dos seus aprimoramentos frente às necessidades emergentes, como no contexto da pandemia mencionada anteriormente.

Nesse cenário, já prevendo uma disseminação da informação em diferentes suportes, tem-se estudado desde o final do século anterior como o design influencia na experiência dos usuários.

O termo "Experiência do Usuário" foi usado pela primeira vez por Donald Norman em meados de 1990, em The Design of Everyday Things. Norman é um especialista em ciências cognitivas e é mundialmente conhecido por seus estudos sobre a maneira como o design influencia e facilita a vida das pessoas que utilizam produtos projetados.

Segundo Norman (2006, p. 48 apud GASPARETTO; PEDROZO; OLIVEIRA, 2016, p. 118) a mente humana trabalha com modelos mentais e conhecer tais modelos facilita a comunicação entre o design e o usuário. Para ele, os mesmos princípios que se aplicam aos objetos do cotidiano são aplicados à web e às mais variadas formas de produtos interativos em altas ou baixas tecnologias. Em suas pesquisas Normam argumenta que conhecer o ser humano deve ser o foco e que tudo deve ser centrado no modo como ele interage com o mundo.

Aplicando esses conhecimentos às tecnologias móveis, por exemplo, é possível obter informações tais como: Como se dá o sucesso ou não de determinado aplicativo em detrimento de outro do mesmo segmento; Por quais tipos de aplicações os usuários se sentem mais atraídos e instigados; Como os usuários interagem nos aplicativos; Quais são suas preferências no contexto educativo? Entre tantas informações que se é possível obter.

Conhecer o perfil e as preferências dos usuários demandaria uma série de pesquisas e métodos investigativos baseados em relatórios das mais diferentes naturezas. Uma outra alternativa seria partir de um projeto de Design Colaborativo, para juntamente com esses usuários elaborar aplicações mais condizentes com as suas necessidades e preferências.

No design participativo, o processo é concentrado no designer, em contato com os usuários para participar de etapas do projeto.

Segundo Garone e Nesteriuk (2020, p. 246), o termo design colaborativo não é exclusivo do Design, se fazendo presente em diversas áreas, visto que a colaboração é um fenômeno inerente aos processos humanos.

Fontana, Heemann e Ferreira, (2012, p. 375 apud GARONE; NESTERIUK, 2020, p. 247), definem a colaboração no design como "[...] o esforço recíproco entre pessoas de iguais ou diferentes áreas de conhecimento, separadas fisicamente ou não, com um objetivo comum de encontrar soluções que satisfaçam a todos os interessados. [...]".

Nesse sentido, é importante salientar que há o design colaborativo e também o codesign que apesar de parecerem iguais, são práticas diferentes quanto à participação dos usuários no desenvolvimento dos produtos. 
Para Alves e Maciel (2016, p. 18 apud GARONE; NESTERIUK, 2020, p. 248), o codesign envolve mais do que consultar usuários - engloba conseguir o envolvimento ativo do usuário na clarificação do problema e no desenvolvimento de soluções de design. Assim, no codesign o designer é mediador dos usuários em um processo de colaboração.

Diante do exposto, vê-se, portanto, o surgimento de um ramo bastante atrativo e promissor para os designers, tendo em vista que as interfaces gráficas das tecnologias móveis ganham cada vez mais visibilidade com os smartfones e agora começam a se destacar também na EAD.

Esse cenário a partir de 2017 ganha força também no ensino superior, onde segundo o relatório Diretrizes de Política Pública para o Ensino Superior Brasileiro, publicado em 2017, afirma que a nova política pública para o ensino superior deve prever que as instituições possam utilizar as possibilidades do ensino digital, com liberdade para inovar e introduzir adaptações permanentes às mudanças registradas nos ambientes tecnológicos e sociais, facilitando um maior acesso ao conhecimento (SEMESP, 2017 apud AMARAL; GONÇALVES, 2020, p. 210).

Nesse contexto, percebe-se que os dispositivos móveis têm a possibilidade de subsidiar as diferentes demandas que se apresentam em todos os setores da educação, com fortes indícios de se consolidarem neste ramo. As interfaces, por sua vez, tendo em vista seu aperfeiçoamento, ganham a oportunidade de estreitarem essa parceria que se fortalece cada vez mais entre a educação e as tecnologias, contribuindo assim para progresso da EAD em nosso país.

\section{Considerações finais}

A Educação a Distância (EAD), como já mencionado, se instaura como uma ruptura com o sistema tradicional de ensino, pois parte da perspectiva de ensino autônomo, não linear e convergente com os mais variados recursos tecnológicos da contemporaneidade.

Ao longo dos anos, instituições e docentes têm revisado suas estratégias de atuação e incentivado a pesquisa neste âmbito, objetivando, assim, o desenvolvimento de novas técnicas que sejam capazes de se adaptar às condições variáveis dos estudantes e às demandas formativas no contexto contemporâneo da sociedade da informação e do conhecimento, com mudanças constantes e aceleradas pela tecnologia.

Conforme exposto por Amaral e Gonçalves (2020, p. 210), a incorporação de tecnologias digitais no ensino é fundamental para democratizar o acesso a uma educação de qualidade e equidade, ampliar a interiorização e melhorar os processos de ensino e aprendizagem.

Nesse sentido, encontra-se a EAD, modalidade de educação caracterizada pela separação geográfica entre alunos e professor, onde faz-se necessário o uso de estratégias específicas para esse contexto, além de ferramentas tecnológicas que possibilitam os mais diversos tipos de interação 
que essa modalidade exige, por exemplo, entre o aluno-conteúdo, aluno-professor e aluno-aluno, portanto, para subsidiar todos esses processos tem-se as interfaces gráficas.

As interfaces gráficas são confeccionadas por equipes de desenvolvedores de softwares e designers que atuam promovendo tais interações, por meio de estratégias projetuais. Para Krug (2001, p. 134), "em muitos casos os designers querem construir produtos que tenham uma ótima aparência, já os desenvolvedores querem construí-los com recursos interessantes, originais e elegantes". No processo de confecção das interfaces ambos os lados possuem o mesmo peso, visto que tanto características visuais quanto técnicas são de igual relevância para o resultado final.

Por meio das interfaces gráficas, o design atua na EAD promovendo diferente ações, de modo a tornar a comunicação, apresentação e manipulação de diferentes elementos mais eficiente para o usuário.

Sabe-se que a interface do usuário é a janela para o software, ou seja, "atua como uma espécie de tradutor, mediando entre as duas partes, tornando uma sensível e compreensível para a outra" (JOHNSON, 2001, p. 17). Diante dessa característica, entende-se que a interface é capaz de moldar a percepção do usuário quanto a qualidade e eficácia de um sistema, aplicação ou ferramenta.

Nesse ponto, onde já é possível compreender a importância das interfaces gráficas para a EAD, tem-se as interfaces gráficas dos dispositivos móveis, como os smartphones, por exemplo, que atualmente estão entre os dispositivos tecnológicos mais utilizados pelas pessoas. Os celulares smartphones passam a ganhar também visibilidade no contexto da EAD, cenário impulsionado ainda mais pela pandemia do Corona Vírus que de uma hora para a outra isolou as pessoas em suas casas, obrigando as escolas a pensarem rapidamente em alternativas para as aulas presenciais.

Dessa forma, tem-se então um leque de possibilidades para os designers de interfaces, diante do destaque que as interfaces móveis vêm ganhando nesse contexto educativo.

$\mathrm{Na} \mathrm{EAD}$, os designers muitas vezes atuam na estruturação e no aprimoramento das interfaces e/ou nos recursos que irão compô-la, contudo, se a interface do usuário for mal projetada, a capacidade de o usuário aproveitar todo o poder computacional e conteúdo de informações de uma aplicação, pode ser seriamente afetada. Na realidade, "uma interface fraca pode fazer com que uma aplicação, em outros aspectos, bem projetada e solidamente implementada, falhe" (PRESSMAN, 2005, p. 630). Por esse motivo, tem-se a possibilidade de aplicação de diferentes estratégias que visem colaborar com a efetividade do trabalho dos designers na confecção e aprimoramento das interfaces, por meio de projetos baseados na experiência dos usuários. Uma dessas estratégias é o design colaborativo ou o codesign, visando incluir os usuários no processo de concepção dos designers, de modo a torná-los coprodutores das interfaces, contribuindo assim para a assertividade e o sucesso dos projetos. 


\section{Referências}

ABREU, Cristiano Nabuco de; EISENSTEIN, Evelyn; ESTEFENON, Susana Graciela Bruno. Vivendo esse mundo digital: impactos na saúde, na educação e nos comportamentos sociais. $1^{\mathrm{a}}$ Ed. Porto Alegre: Artmed Editora, 2013.

AMARAL, Ana Letícia Oliveira; Gonçalves, Berenice Santos. Ensino da fotografia e as Tecnologias Digitais de Informação e Comunicação: um estudo com discentes de uma graduação de Design. In: DATJournal Design Art and Technology, v. 5, n. 1, 2020. Pp. 206-219. Disponível em https://datjournal.anhembi.br/dat/issue/view/11 Acesso em: 27/04/2020.

ASSOCIAÇÃO BRASILEIRA DE EDUCAÇÃO A DISTÂNCIA (ABED). Censo EAD.BR: Relatório Analítico da Aprendizagem a Distância no Brasil 2017/2018. Curitiba: Ibpex, 2019.

BONSIEPE, Gui. Design, cultura e sociedade. São Paulo: Editora Blücher, 2011.

BONSIEPE, Gui. Do Material ao Digital. São Paulo: Editora Blücher, 2015.

CAMPOS, G.B.; PRIOSTE, M. Design de hipermídia: os desafios na construção das interfaces gráficas. In: Anais do 3ํㅡㄹ Congresso Internacional de Pesquisa em Design, Rio de Janeiro. 2005. DONDIS, D. A. Sintaxe da linguagem visual. $3^{\mathrm{a}} \mathrm{ed}$. São Paulo: Martins Fontes, 2007.

DUOLINGO. Aprenda idiomas de graça: agora e sempre, 2020. Disponível em: https://pt. duolingo.com/. Acesso em: 19/04/2020.

EAESP, FGV. Mercado Brasileiro de TI e Uso nas Empresas. $30^{\mathrm{a}}$ Pesquisa Anual do FGVcia da FGV/EAESP. São Paulo: EAESP FGV, 2019. Disponível em: https://eaesp.fgv.br/sites/eaesp.fgv.br/files/noticias2019fgvcia_2019.pdf. Acesso em: 7/04/2020.

EDMODO. Aprenda melhor juntos, 2020. Disponível em: https://www.edmodo.com/. Acesso em: $19 / 04 / 2020$.

FERREIRA, Aurélio Buarque de Holanda. Dicionário Aurélio da Língua Portuguesa. Curitiba: Editora Positivo, 2014.

GARONE, Priscilla Maria Cardoso; NESTERIUK, Sérgio. Modelo de design colaborativo de soluções que envolvem jogos digitais ou seus elementos para a educação a distância. In: DATJournal Design Art and Technology, v. 5, n. 1, São Paulo, 2020. p. 244-263. Disponível em https://datjournal.anhembi.br/dat/issue/view/11. Acesso em: 20/04/2020.

GASPARETTO, Débora Aita; PEDROZO, Danielle Difante; OLIVEIRA, Fernanda Oliveira. Design Conectado: por um mundo de experiências. In: Estudos em Design, v. 24, n. 2, Rio de Janeiro, 2016. Pp 112-131. Disponível em: https://estudosemdesign.emnuvens.com.br/design/article/view/348. Acesso em: 21/04/2020.

GLOBO-G1 SP e SP1. Aplicativo para aulas a distância na rede estadual. São Paulo, 2020. Disponível em: https://g1.globo.com/sp/sao-paulo/noticia/2020/04/04/aplicativo-para-aulas-a-distancia-na-rede-estadual-de-educacao-ja-esta-disponivel-para-alunos-de-sp.ghtml.Acesso em: 23/04/2020.

IBGE Educa. Uso de Internet, televisão e celular no Brasil, 2017. Disponível em: https:// educa.ibge.gov.br/jovens/materias-especiais/20787-uso-de-internet-televisao-e-celular-no-brasil.html\#subtitulo-1. Acesso em 07/04/2020.

IBGE Educa. Diretoria de Pesquisas, Coordenação de Trabalho e Rendimento, Pesquisa Nacional por Amostra de Domicílios, 2017. Disponível em: https://educa.ibge.gov.br/ jovens/materias-especiais/20787-uso-de-internet-televisao-e-celular-no-brasil.html\#subtitulo-1. Acesso em: 07/04/2020.

JOHNSON, Steven. Cultura da interface: como o computador transforma nossa maneira de criar e comunicar. $1^{\text {a }}$ ed. Rio de Janeiro: Zahar, 2001. 
KRUG, Steve. Não me faça pensar! uma abordagem do bom senso à navegabilidade da WEB. $2^{\mathrm{a}}$ ed. São Paulo: Market Books, 2001.

LÉVY, Pierre. As tecnologias da inteligência. Rio de Janeiro: Editora 34, 1993.

LÉVY, Pierre. Cibercultura. Rio de Janeiro: Editora 34, 1999.

LITTO, Fredric M.; FORMIGA, Marcos (orgs). Educação a distância: o estado da arte. São Paulo: Editora Pearson, 2009.

MEC-Ministério da Educação/Gabinete do Ministro. Portaria n. 1.428, de 28 de dezembro de 2018. In Diário Oficial da União. 31/12/2018, Edição 250, seção 1, p. 59. Disponível em: http://www.in.gov.br/materia/-/asset_publisher/Kujrw0TZC2Mb/content/id/57496468/ do1-2018-12-31-portaria-n-1-428-de-28-de-dezembro-de-2018-57496251. Acesso em: $20 / 04 / 2020$.

PRENSKY, M. Digital Native, digital immmigrants. Digital Native immigrants. On the horizon, MCB University Press, Vol. 9, N.5, October 2001. Disponível em: http://www.marcprensky.com/writing/Prensky\%20-\%20Digital\%20Natives,\%20Digital\%20Immigrants\%20 -\%20Part1.pdf Acesso em: 20/04/2020.

TOFFLER, Alvin. Powershift: as mudanças do poder. $1^{\text {a }}$ ed. Rio de Janeiro: Editora Record, 1995. 